\title{
Revamping Robotics Education via University, Community College and In- dustry Partnership - Year 1 Project Progress
}

\section{Prof. Aleksandr Sergeyev, Michigan Technological University}

Aleksandr Sergeyev is currently an Associate Professor in the Electrical Engineering Technology program in the School of Technology at Michigan Technological University. Dr. Aleksandr Sergeyev earned his bachelor degree in Electrical Engineering at Moscow University of Electronics and Automation in 1995. He obtained the Master degree in Physics from Michigan Technological University in 2004 and the $\mathrm{PhD}$ degree in Electrical Engineering from Michigan Technological University in 2007. Dr. Aleksandr Sergeyev's research interests include high energy laser propagation through the turbulent atmosphere, developing advanced control algorithms for wavefront sensing and mitigating effects of the turbulent atmosphere, digital inline holography, digital signal processing, and laser spectroscopy. Dr. Sergeyev is a member of ASEE, IEEE, SPIE and is actively involved in promoting engineering education.

\section{Dr. Nasser Alaraje, Michigan Technological University}

Dr. Alaraje is an Associate Professor and Program Chair of Electrical Engineering Technology in the School of Technology at Michigan Tech. Prior to his faculty appointment, he was employed by Lucent Technologies as a hardware design engineer, from 1997- 2002, and by vLogix as chief hardware design engineer, from 2002-2004. Dr. Alaraje's research interests focus on processor architecture, System-onChip design methodology, Field-Programmable Logic Array (FPGA) architecture and design methodology, Engineering Technology Education, and hardware description language modeling. Dr. Alaraje is a 2013-2014 Fulbright scholarship recipient at Qatar University, where he taught courses on Embedded Systems. Additionally, Dr. Alaraje is a recipient of an NSF award for a digital logic design curriculum revision in collaboration with the College of Lake County in Illinois, and a NSF award in collaboration with the University of New Mexico, Drake State Technical College, and Chandler-Gilbert Community College. The award focused on expanding outreach activities to increase the awareness of potential college students about career opportunities in electronics technologies. Dr. Alaraje is a member of the American Society for Engineering Education (ASEE), a member of the ASEE Electrical and Computer Engineering Division, a member of the ASEE Engineering Technology Division, a senior member of the Institute of Electrical \& Electronic Engineers (IEEE), and a member of the Electrical and Computer Engineering Technology Department Heads Association (ECETDHA).

\section{Prof. Scott A Kuhl, Michigan Technological University}

Scott Kuhl is an Associate Professor of Computer Science and an Adjunct Associate Professor of Cognitive \& Learning Sciences at Michigan Technological University. He received his Ph.D. in Computer Science from the University of Utah in 2009. His primary research interests include immersive virtual environments, head-mounted displays, and spatial perception. A link to his web page can be found at http://www.cs.mtu.edu/.

\section{Mr. Mark Highum, Bay de Noc Community College}

Mark Highum is currently the Division Chair for Technology at Bay College. He is the Lead Instructor for Mechatronics and Robotics Systems and also teaches courses in the Computer Network Systems and Security degree. Mark holds a Master's in Career and Technical Education (Highest Distinction) from Ferris State University, and a Bachelor's in Workforce Education and Development (Summa Cum Laude) from Southern Illinois University. Mark is a retired Chief Electronics Technician (Submarines) and served and taught as part of the Navy's Nuclear Power Program. Mark is active with SkillsUSA and has been on the National Education Team for Mechatronics since 2004. - See more at: https://www.asee.org/public/person\#sthash.ca7on89C.dpuf

Mr. Mark Bradley Kinney, Bay de Noc Community College 
Mark Kinney became the Dean for Business and Technology in July of 2012, but first came to Bay College as the Executive Director of Institutional Research and Effectiveness in February 2009. Prior to that, Mark served as the Dean for Computer Information Systems and Technology at Baker College of Cadillac and as the Chief Operating Officer and network administrator at Forest Area Federal Credit Union. He has taught a wide range of courses in the computer information systems discipline and holds certifications in both Microsoft Excel and Microsoft Access. Mark has a Master's in Business Administration with a concentration in Computer Information Systems from Baker College, as well as a Bachelor's in Business Leadership and an Associate's of Business from Baker College. Currently, Mark is completing his dissertation in fulfillment of the requirements of a Doctorate in Educational Leadership from Central Michigan University.

\section{Mr. James Walker, Michigan Technological University}

James Walker holds an M.S. in computer science from Michigan Technological University, where he currently performs virtual reality research in pursuit of his Ph.D. He was the lead software developer for the robotics simulator described in this paper. 


\title{
Revamping Robotics Education via University, Community College and Industry Partnership - Year 1 Project Progress
}

\begin{abstract}
Recently, educators have worked to improve STEM education at all levels, but challenges remain. Capitalizing on the appeal of robotics is one strategy proposed to increase STEM interest. The interdisciplinary nature of robots, which involve motors, sensors, and programs, make robotics a useful STEM pedagogical tool. There is also a significant need for industrial certification programs in robotics. Robots are increasingly used across industry sectors to improve production throughputs while maintaining product quality. The benefits of robotics, however, depend on workers with up-to-date knowledge and skills to maintain and use existing robots, enhance future technologies, and educate users. It is critical that education efforts respond to the demand for robotics specialists by offering courses and professional certification in robotics and automation. This, NSF sponsored, project introduces a new approach for Industrial Robotics in electrical engineering technology (EET) programs at Michigan Tech and Bay de noc Community College. The curriculum and software developed by this collaboration of two- and four-year institutions will match industry needs and provide a replicable model for programs around the US. The project also addresses the need for certified robotic training centers (CRTCs) and provides curriculum and training opportunities for students from other institutions, industry representatives, and displaced workers. Resources developed via this project will be disseminated through a variety of means, including workshops, conferences, and publications. This paper addresses the developments of the project during its first year phase.
\end{abstract}

\section{Introduction}

Many existing jobs will be automated in the next 20 years, and robotics will be a major driver for global job creation over the next five years. These trends are made clear in a study conducted by the market research firm, Metra Martech, "Positive Impact of Industrial Robots on Employment". Many repetitive, low-skilled jobs are already being supplanted by technology. However, a number of studies have found that in the aggregate, the robotics industry is creating more jobs than the number of jobs lost to robots. For example, the International Federation of Robotics (IFR) estimates that robotics directly created 4 to 6 million jobs through 2011 worldwide, with the total rising to eight to 10 million if indirect jobs are counted. The IFR projects that 1.9 to 3.5 million jobs related to robotics will be created in the next eight years ${ }^{2}$. The rapid growth of robotics and automation, especially during the last few years, its current positive impact and future projections for impact on the United States economy are very promising. Even by conservative estimates ${ }^{1}$, the number of robots used in industry in the United States has almost doubled in recent years. In the manufacturing sector, the recent growth was $41 \%$ in just three years - the number of robots per 10,000 workers employed in 2008 was 96 and reached 135 in 2011. The automotive sector in the United States relies heavily on robotics as well - China produces more cars than the US, but the number of robots used in vehicle manufacture in China is estimated at 40,000 compared to 65,000 in US. From 2014 to 2016, robot installations are estimated to increase about $6 \%$ a year, resulting in an overall 3-year increase $^{1}$ of $18 \%$. Likewise, industrial robot manufacturers are reporting $18-25 \%$ growth in orders and revenue year on year. While some jobs will be displaced due to the increased rollout 
of robots in the manufacturing sector, many will also be created as robot manufactures recruit to meet growing demand. Furthermore, jobs that were previously sent offshore are now being brought back to developed countries due to advances in robotics. For example, Apple now manufactures the Mac Pro in America and has spent approximately $\$ 10.5$ billion in assembly robotics and machinery ${ }^{3}$. In March 2012, Amazon has acquired Kiva Systems, a warehouse automation robot, and in 2013 deployed 1,382 Kiva robots in three Fulfillment Centers. This initiative has not reduced the number of employees at Amazon; in fact, it added 20,000 full-time employees to its US fulfillment centers alone. Such rapid growth of robotic automation in all sectors of industry will require an enormous number of technically sound specialists with the skills in industrial robotics and automation to maintain and monitor existing robots, enhance development of future technologies, and educate users on implementation and applications. It is critical, therefore, that educational institutions adequately respond to this high demand for robotics specialists by developing and offering appropriate courses geared towards professional certification in robotics and automation. In addition, certified robotic training centers (CRTCs) will be in high demand by industry representatives and displaced workers who need to retool their skills. This project aims to demonstrate and test an effective approach for teaching emerging topics of Industrial Robotics in electrical engineering technology (EET) programs at both the university and community college levels. The curriculum and software developed in this initiative between two-year and four-year institutions will match current industry needs and will provide a replicable model for the EET programs across the country. The project also addresses the need for CRTCs and provides curriculum and training opportunities for students from other institutions, industry representatives, and displaced workers.

The overall goal of the project is to help meet the nation's forthcoming need for highly trained Industrial Robotics workers. Strategies include developing, testing, and disseminating an updated, model curriculum, laboratory resources, and simulation software package suitable for use in both 2- and 4-year EET programs. To complement this effort, outreach to K-12 students and teachers will work to enlarge the pipeline and diversity of students interested in careers in robotics. Programs will also be offered to students at other institutions and to workers in industry to broaden impact.

\section{Specific project objectives include:}

1. Provide Electrical Engineering Technology (EET) two-year and four-year students with current and relevant skills in Industrial Robotics by:

a. Updating both the two-year and four-year electrical engineering technology curriculum to include skills in industrial robotics relevant to current industry needs.

b. Enhancing the existing Industrial Robotics laboratory at Michigan Tech and establishing a similar laboratory at Bay Community College to demonstrate the value of state-of-the-art, hands-on training experiences and support the course changes.

2. Provide "stand-alone" programs to train and certify students from other institutions, industry representatives, and displaced workers.

3. Develop new "RobotRun" robotic simulation software and make it available at no cost for adaptation by the other institutions. This will allow current concepts related to industrial robotics to be taught even in locations without access to current robotics hardware.

4. Train faculty members at similar institutions to build expertise in Industrial Robotics using state-of-the-art FANUC Robots. 
5. Develop a pipeline and encouragement for 2-year students (particularly underrepresented students, many of whom attend community colleges) to explore options in 4-year EET degree programs.

6. Conduct robotics-oriented seminars for K-12 teachers to expand their knowledge in engineering and science and increase the awareness of the role the field of robotics plays in STEM education.

7. Conduct robotic workshops for high school students to increase their interest in STEM fields, utilizing the appealing concepts of robotics and automation to attract participants.

8. Disseminate the new curriculum and software widely to significantly impact the future electrical engineering technology workforce by encouraging enhancements in other EET programs.

\section{Project Rationale and Need}

Workforce Need: In 2014, ManpowerGroup surveyed nearly 40,000 employers across 41 countries and territories as part of its annual Talent Shortage Survey ${ }^{4}$ and identified that employers are having the most difficulty finding the right people to fill jobs in Japan $81 \%$, Brazil $63 \%$ and the US 40\%. In fact, two occupations in the US: technicians (primarily production/operations, engineering or mathematics) and engineers top the list of 10 jobs employers have difficulty filling. In addition, the American Society for Training and Development (ASTD) reports major skill gaps in the US. The 2013 ASTD report states that US organizations spent $\sim \$ 164.2$ billion on employee learning ${ }^{5}$ in 2012 . The US is facing an alarmingly high replacement need for STEM professionals 6,7 . For instance, the projected replacement rate in mathematical science is $29.5 \%$, in physics it is $28.5 \%$, in mechanical engineering it is $26 \%$, and in electrical engineering it is $23 \%$. It is estimated that during this decade, employers will need to hire about 2.5 million STEM workers, drawing largely from engineering and engineering technology programs that are known for equipping graduates with the tools to enter the workforce, for the first time, prepared $^{8,9}$. This requires an innovative curriculum that involves hands-on opportunities for practical problem solving.

On the one hand, the pipeline for an educated future workforce is already in place. According to data from the Current Population Survey ${ }^{7}$, the share of the population aged 16 and over who have college degrees roughly doubled over the past three decades, as did the share of those with some college education. However, there is concern that the US is still not preparing a sufficient number of students, teachers, and professionals in STEM areas ${ }^{10-13}$. In a recent international assessment of 15-year-old students, the US ranked 28th in math literacy and 24th in science literacy. Moreover, the US ranks 20th among all nations in the proportion of 24-year-olds who earn degrees in natural science or engineering ${ }^{10}$. In the National Academy of Sciences (NAS) report "Rising above the Gathering Storm: Energizing and Employing America for a Brighter Economic Future," as well as in the Administration's American Competitiveness Initiative ${ }^{14}$, five recommendations were made targeted at improving STEM education. These five recommendations seek to 1) increase the supply of new STEM teachers, 2) improve the skills of current STEM teachers, 3) enlarge the pre-collegiate pipeline, 4) increase postsecondary degree attainment, and 5) enhance support for graduate and early-career research ${ }^{10}$. Our approach aims to address, through short and long term goals, each of these recommendations. 
Educational Need: Robotics is a great tool to promote STEM fields. Educators have been making measurable progress toward improving STEM education from primary to tertiary levels of education, but challenges remain. Given the current shortage of student interest in STEM education, increased attention has been given to the appeal and attraction of Robotics. The interdisciplinary construction of robots, which involves motors, sensors, and programming, makes it a useful pedagogical tool for all STEM areas. The novelty of robotics is instrumental in attracting and recruiting diverse STEM students. In the classroom, robotics can easily be used to introduce a variety of mandatory skills needed to pursue a variety of STEM career paths ${ }^{14-17,22 \text {, }}$ 24. More specifically, a robotics platform advances students' understanding of both scientific and mathematical principles ${ }^{17,18}$, develops and enhances problem-solving techniques ${ }^{17,18,20-23}$, and promotes cooperative learning ${ }^{17-19}$.

While robotics can be used as an interdisciplinary STEM learning tool, there is also a strong need for industrial certification programs in robotics automation. More and more robots are designed to perform tasks that people may not want to do, such as vacuuming, or are not able to do safely, such as dismantling bombs. They have changed the lives of Amyotrophic Lateral Sclerosis (ALS) patients by giving them the ability to speak after their vocal cords have failed, and have sparked our imagination in space exploration (not to mention our fascination with characters like R2D2). As many have put it, robots do our dirty, dangerous, and/or dull work. Millions of domestic/personal robots are already on the market worldwide, from lawn mowers to entertainment robots $^{25}$. As a result, popular interest in robots has increased significantly ${ }^{16-28}$. Global competition, productivity demands, advances in technology, and affordability will force companies to increase the use of robots in the foreseeable future ${ }^{39-41}$. While the automotive industry was the first to use robotics, aerospace, machining, and medical industries now also rely on robotic automation ${ }^{42,43}$. More than ever, trained and certified specialists are needed to maintain and monitor existing robots and to develop more advanced robotic technologies ${ }^{39,44-46}$.

As mentioned, robotics can be used as an interdisciplinary, project-based learning vehicle to teach STEM fundamentals ${ }^{29-31}$. Understanding the valuable role robotics education plays in helping students understand theoretical concepts through invention and creation, many universities include components of robotics research in curricular offerings ${ }^{35}$. It is widely recognized that robotics is a valuable learning tool that can enhance overall STEM comprehension and critical thinking ${ }^{29,36-38}$. As a result of these benefits and industry needs, new programs in robotics automation and applied mobile robots are popping up in the US and abroad. Industrial help from Microsoft, FANUC Robotics America Inc., and MobileRobots Inc., is essential to the growth of these programs. The objectives behind robotic programs are clear: 1) in the short term, robotics education fosters problem solving skills, communication skills, teamwork skills, independence, imagination, and creativity ${ }^{32-34}$; and 2) in the long term, robotics education plays a key role in preparing a workforce to implement $21^{\text {st }}$ century technologies. Currently, few universities offer specific robotics degrees. For instance, Worcester Polytechnic Institute (WPI) has offered a Bachelor of Science in Robotics Engineering ${ }^{50}$ since 2007. Universities that have graduate degrees focused on robotics include Carnegie Mellon University, MIT, UPENN, UCLA, WPI, and the South Dakota School of Mines and Technology (SDSMT). Michigan State University has a well-established Robotics and Automation laboratory, but it is utilized for graduate robotics courses and research. Very few universities across the US offer a degree and/or certification specifically in robotics automation. In fact, Lake Superior State 
University (LSSU) is one of very few universities in Michigan that specializes in robotics automation; however, it does not have a program to certify industry representatives ${ }^{47}$. With few focused industrial robotics programs, undergraduate industrial robotics training often occurs in electrical engineering technology programs, the focus of the proposed program. Training in robotics automation is especially important to Michigan's economy. A major decline in automotive manufacturing jobs has left many areas in Michigan with high rates of unemployment. Baraga County, located 15 miles south of Michigan Tech, has one of the nation's highest rates of unemployment. Yet, Michigan has an unmet need for workers in robotics jobs ${ }^{26 \text {, }}$ 48. Filling these jobs, however, requires workers trained and certified in the following skill sets: designing, testing, maintaining, and inspecting robotic components; troubleshooting robot malfunctions; using microcomputers, oscilloscopes, hydraulic test equipment, microprocessors, electronics, and mechanics; and reading blueprints, electrical wiring diagrams, and pneumatic/hydraulic diagrams. Driven by industry needs, the new curriculum designed in this project will be adapted for both two- and four-year programs. The project aims to address the current US workforce need for properly prepared STEM professionals, train current industry representatives and displaced workers in robotics automation, educate K-12 teachers with the current art of industrial robotics, and promote STEM fields among K-12 students.

\section{Task 1: Robotics Automation Curriculum Development for EET Programs:}

This project will have a significant impact on the curriculum at both institutions - Bay College and Michigan Tech. During this collaborative initiative, a broad spectrum of educational material will be developed and made available between institutions for adaptation. Figure 1 depicts the proposed models in robotics curriculum development which will impact three different educational groups: 1) two- and four-year institutions; 2) students from other universities and community colleges, industry representatives, and displaced workers; and 3) K-12 teachers and high school students. The proposed curriculum changes are presented below.

Model Robotics Curriculum for Two- and Four-Year Educational Institutions: The robotics curriculum at Michigan Tech will be enhanced by adding a new course Robotics Vision Systems and by developing new, state-of-the-art educational robotic simulation software called RobotRun. Bay College has no robotics-related courses in its current curriculum. Through this project, will add two new courses and utilize the open-source robotic training software (developed through this project) in the classroom. Working closely with Michigan Tech, Bay College will modify existing Real-Time Robotics System course for use at the community college level. During the project, faculty from both partner institutions will collaborate in the development of the new Robotics Vision course and the robotics training software. Both the new course and the robotic training software will be adapted for use in the Bay College curriculum. Bay College is currently in the process of developing a multi-skilled technician certificate program that will serve as a broad-based entry point for students interested in careers ranging from automation, to advanced manufacturing, to industrial systems control, and more. The robotics courses being developed as part of the partnership with Michigan Tech will fit seamlessly into this degree to provide students with an entry-level understanding of robotics and automation technology. Furthermore, the courses will be included as part of the articulated transfer program designed for students interested in a more intensive study of robotics. These courses will also be available to preengineering students, which is also an articulated transfer program to Michigan Tech. Students at 
Bay College will benefit from these curriculum additions in numerous ways, including expanded exposure to advanced technologies, better career preparation, and increased options for transfer to Michigan Tech.

Building Upon the Strong Foundation of Michigan Tech's existing course: Real-Time Robotics Systems: As shown in Figure 1, the current curriculum at Michigan Tech in robotics automation includes one Real-Time Robotics Systems course (4 credit hour: 3 hours of recitation and 3 hours of weekly lab) covering all the theoretical and practical aspects of the knowledge required for technologists involved in the robotics automation industry. The course introduces the science and technology of mechanical manipulations and robotics systems control. A broad range of robotics topics is covered, including: sensors, end-effectors, and actuators. Essentially, this course is the building block for future coursework in the mechanics, control, and programming of robotic systems. Designed from a manufacturing perspective, the course addresses robots in an isolated manner while exploring the broad topic of industrial work cells that contain a robot. This includes robot automation and all related technology needed to integrate the robot with the work environment and with the enterprise database. The course also addresses the major aspects of design, fabrication, and robotic-enabling systems. Design aspects involve determining: specifications for a robot, configurations, and what sensors and actuators should be used. Considerable attention is currently dedicated to safety procedures of operating robotics platforms. The currently used FANUC Roboguide software package allows students to learn the structure of the programming language commonly used in the field of robotics for off-line programming. After receiving sufficient off-line programming training and passing the safetyrelated test, students implement their knowledge and perform laboratory experiments that involve hands-on programming and operation of a state-of-art FANUC industrial robot. This course offers the foundation of an educational platform for developing and implementing an effective curriculum model in Robotics Automation. Close collaboration with industry in the initial design of this course also helped the PI to advance an industrial certification program that is endorsed by industry. Students who successfully complete the course are certified by Dr. Sergeyev and are issued a FANUC industrial certificate in "Handling Tool Operation and Programming." To further promote the course development and make the course offering model more flexible, Dr. Sergeyev developed two derivatives of the course. The first, a hybrid version of the course, has been successfully implemented several times since 2012. In this version of the course, the theory, quizzes, and exams are delivered online, but students still have an opportunity for hands-on training during weekly 3 -hour labs. This model allows for more flexible scheduling of the class, which in turn helps students who work while attending school. The second course derivative involves an intense two-week structure with the same amount of theory and hands-on practices in a condensed time period. The first week involves an introduction to the theoretical content, culminating in the midterm exam. In the second week, students are completely immersed in the hands-on activities of operating and programming FANUC industrial robots. The second week culminates with a 2-hour certification/final exam. The two-week intense course model has proven to be very effective, and has become very popular among students at Michigan Tech in a variety of disciplines. Since 2009, Dr. Sergeyev, a FANUC certified instructor, has trained and awarded industrial certificates to more than a hundred students. Building upon the foundational course in place at Michigan Tech, Bay College will adapt and implement all the derivatives of the Real-Time Robotics System course in order to provide students with flexible course offerings and certification options. 
New Course: Robotics Vision Systems: Nearly any robot currently used in industry is equipped with a vision system. Vision systems are being used increasingly with robot automation to perform common and sometimes complex industrial tasks, such as: part identification, part location, part orientation, part inspection and tracking. The vision system provides the robot "eyes" needed to perform complex manufacturing tasks. The Robotics Vision Systems course will be designed as a 4 credit hour course ( 3 hours of recitation and 3 hours of weekly lab). The course will introduce topics on: 1) safety, including laser safety; 2) basics of optics and image processing; 3) setting up lightning conditions required for the successful vision error proofing and camera calibration; 4) teaching tool, application, and calibration frames; 5) performing 2D calibration and 2D single and multiview robotic processes; 6) performing 3D calibration and 3D single view robotic vision processes. Hands-on training is an integral part of any course developed in the School of Technology at Michigan Tech, and this course is no exception. It will include 12 laboratory exercises, totaling 36 hours, with the goal of providing students the opportunity to configure and execute real-life, industry comparable, robotic vision scenarios. The course will be similar to the existing Real-Time Robotics Systems' rigorous assessment strategy and will culminate in a two-hour certification exam. Students successfully passing the exam will receive a certificate in $i R$ Vision $2 D$ issued by the FANUC certified instructors - Dr. Sergeyev at Michigan Tech or Mr. Highum at Bay College. In addition to the traditional offering, two derivatives (a hybrid and 2-week intense version) of the Robotics Vision Systems will be developed and implemented at both institutions - Bay College and Michigan Tech.

New Open-Source Robotic Training Software: RobotRun software will act as a simulator where a user can write a program and then view how that program performs when run on a virtual 3D robotic arm displayed on the screen. Although robotics play an essential role at a variety of manufacturing facilities, there is currently no accessible and free software that can give students the opportunity to learn about using the robotic hardware without purchasing expensive, complex, proprietary software packages. This software is intended to be used alongside the other training materials developed as a part of this project, but it will also be made available online for anybody to download and use. The RobotRun software will show a 3D, animated rendering of a robotic arm that can be controlled via an intuitive programming language that is similar to the programs used to program real robotic arms. The programming language in our robotic arm simulator software will provide all of the basic commands that exist in real-world robotics systems so that students can easily transfer the knowledge gained from the developed software to real-world robotic arms. The software will allow the user to control where the end-effector should jog, at what speed and type of motion termination, how many times it should repeat the movement, and other common robotics controls. Besides the option of jogging the robot and performing programming tasks, the software will be configured to present users with different scenarios that mimic real-world industrial scenarios such as pick and place, palletizing, welding, painting, etc. The program will also allow users to load and save their programs so that they can turn them in to an instructor for grading. The new software will provide all options necessary to teach the required skills in robotics handling tool operation and programming. It will be simple, without features of expensive robotic simulation software packages that are designed for in-depth industrial simulations and are not typically used in educational settings. The open-source and free nature of the developed RobotRun training software will have a significant and broad impact by: 1) enabling institutions unable to obtain expensive industrial robots to adapt and teach the 
developed robotics courses; 2) providing K-12 teachers with the opportunity to promote STEM education to students by introducing the appealing concept of robotics via an interactive training environment, at no cost to K-12 institutions; 3 ) providing displaced workers wanting to improve their robotics skills with an intuitive, interactive and complete tool to succeed.

\section{Task 2: Curriculum for Students from any Institution, Industry, and Displaced Workers}

While robots play a role in all STEM fields, robots are key components of most manufacturing industries - from health to automotive sectors. Robotic automation has been embraced as a way to stay globally competitive, and to reduce the reliance on manual labor to perform redundant tasks. If the US doesn't want to outsource, we need to automate. To provide support for the industry, educational institutions need to: 1) develop a training curriculum with industrial certification available to students from institutions where a robotics curriculum is not available; this will make those students more valuable in the job market; 2) provide effective, certified training to industry representatives who need to retool their skills to match rapidly developing technologies, especially in the field of robotics automation; 3) provide displaced workers with the opportunity to enhance, or acquire new, skills in robotics and enter the in-demand robotics job market. Certified curriculum development for all three categories is addressed in this proposal. Michigan Tech's existing industrial certification program will be enhanced by offering two additional FANUC certificates. The PI, Dr. Sergeyev will assist faculty from Bay College in establishing an industrial certification program at Bay College as well. Training materials, developed by the PI, for the existing certifications will be made available to Bay College for adaptation. Bay College faculty will be fully engaged in the development of all training materials for the two new certificates.

Certification 1: Handling Toll Operation and Programming (32-hour course)—In place at Michigan Tech; to be adapted for Bay College in this project. The course is designed to be both practical and progressive. The content offers easily applied guidance to personnel involved in manufacturing with current robotic systems on site, or who may be asked to engage in implementing robotic systems in the near future. The course includes a discussion of scholarly and practical robotic topics ranging from kinematics and programming to practical application areas and economic concerns. Topics include: the development of industrial robotics; an overview of the mechanical design, control, programming, and intelligence; organizational and economic aspects; robotics in operation and various applications. Hands-on experience is an essential part of this course and will occupy $70 \%$ of course time. The lab exercises are devoted to practical aspects of programming FANUC Robotics robots. This 32-hour course is designed to be offered partially online. The first 16 hours are devoted to theoretical content delivered online. The remaining 16 hours provide extensive hands-on experience working in the lab at Michigan Tech (or at Bay College in the near future) manipulating and programming FANUC industrial robots. The course culminates in a certification exam in which the participants will have to demonstrate an understanding of theoretical background as well as the ability to program the robot for a task given by the instructor. Participants successfully passing the exam will receive a certificate issued by a FANUC-certified instructor. Due to the nature of the course, it can be offered on demand and conducted during weekends, students' breaks or in the summer. This flexibility has proven successful in attracting students from other institutions, industry representatives, and displaced workers. Feedback from past participants of the Michigan Tech 
training sessions showed very positive results. Students indicated that the partially online delivery approach not only saves travel time and money, but also allows participants to be more focused on the hands-on part of the course, thereby providing a more effective learning environment.

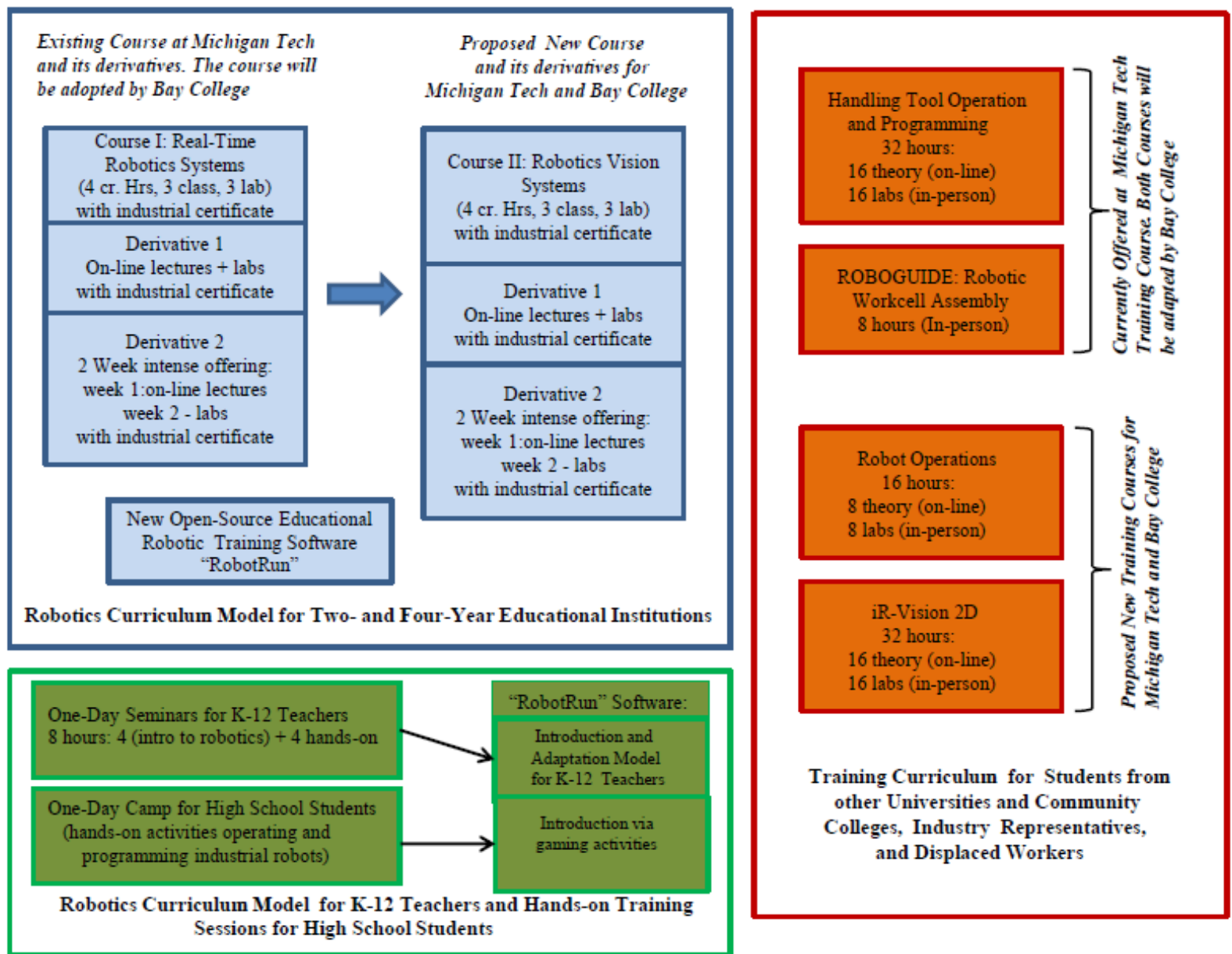

Figure 1: Proposed Robotics Automation Curriculum Development

Certification 2: Roboguide - Robotic Workcell Assembly (8-hour course)—In place at Michigan Tech; to be adapted for Bay College. FANUC Roboguide software is widely used in industry; therefore, there is a great need to train workers in this software. The PI has developed an 8-hour training course that provides participants with a foundation for understanding all software features. By the end of the course, students assemble a fully functional virtual robotic workcell that includes the robot, end-effector, several fixtures and industrial parts that the robot can manipulate. Students program the robot to execute "pick and place" operation, run simulation in step-by-step and production modes, and compile a file that can be further transmitted to the physical FANUC robot for real-time production. This one-day training can be offered on demand and in conjunction with the other existing and under development certification courses. 
Certification 3: Robot Operations (16 hours)—New, to be developed for Michigan Tech and Bay College. There is a great demand in the industrial sector for robot operators that don't necessarily need to have very in-depth programming and theoretical skills. This course is intended for the person who operates or may be required to perform basic maintenance on FANUC robots via the standard application software package. It will teach students how to safely power up, power down, jog the robot to predefined positions, and set up different frames of operation. In addition, it will cover tasks and procedures needed to recover from common program and robot faults, and teach basic programming skills. The course will not address the set-up and operation of specific software features and options nor will it teach in-depth programming skills. These are covered in the 32-hour Handling Toll Operation and Programming course.

Certification 4: iR-Vision 2D (32-hour course)—New, to be developed for Michigan Tech and Bay College. Nearly any robot currently used in industry is equipped with a vision system. Vision systems are being used increasingly with robot automation to perform common and sometimes complex industrial tasks, such as: part identification, part location, part orientation, part inspection and tracking. In other words, the vision system is the robot's "eyes" needed to perform complex manufacturing tasks. This new course will teach students how to set up, calibrate, teach, test, and modify iRVision applications using FANUC robots. The course will include detailed discussion of hardware and software setup, establishing the communication link between the robot and teaching computer, teaching single- and multi-view processes, and programming. Safety procedures will be integrated into all exercises. As an integral part of this course, a series of lab exercises will be developed to provide hands-on training to reinforce the theory the student has learned. This 32-hour course will be designed with a structure similar to the Handling Toll Operation and Programming course: 16 hours of online and 16 hours of handson training. The course will culminate in a certification exam in which the participants will have to demonstrate an understanding of the theoretical background, as well as, the ability to successfully set up, calibrate, program and utilize the FANUC robot equipped vision system. Participants passing the exam will receive a certificate in $i R$ Vision $2 D$ issued by a FANUC certified instructor. Similar to the other certification courses, it can be offered on demand and conducted during weekends, students' breaks or in the summer.

\section{Task 3: Model Robotics Curriculum for K-12 Teachers and Hands-on Training Sessions for High School Students}

As a way to encourage more (and more diverse students) to consider careers in robotics, faculty members from Bay College and Michigan Tech will promote robotics automation to K-12 teachers and high school students. One-day seminars for K-12 teachers will be conducted at both Michigan Tech and Bay College in Year 2 and 3 of the project. During the seminar, participants will: 1) learn concepts of industrial robotics; 2) learn the basics of programming FANUC industrial robots; 3) try the robotic software "RobotRun"; and 4) work with faculty to consider ways the software can be integrated into the K-12 curriculum. Participating teachers will be provided with 4 hours of theory and 4 hours of hands-on operating and programming with FANUC robots and the "RobotRun" simulation software. To promote the field of robotics directly among the high school students, one "day camp" will be conducted yearly, at both institutions. Students will: 1) learn basic principles of industrial robots; 2) operate and program FANUC industrial robots; 3) utilize the gaming environment of the "RobotRun" simulation 
software to play embedded games and conduct basic programming tasks (in Year 2 and 3). Due to the remote location of Upper Peninsula schools, very few programs targeting STEM fields are available. The proposed camps will provide high school students with the extraordinary opportunity to learn and get engaged in STEM-related activities using the appealing nature of robotics. This early-age engagement in STEM activities will help to create a clear path for the students to continue education through postsecondary institutions.

\section{Task 4: Robotic Automation Laboratories at Michigan Tech and Bay College:}

The School of Technology at Michigan Tech offers high-quality, up-to-date academic programs aimed at meeting the immediate and future needs of industry. As a technology program, we offer significant hands-on lab experiences and applied research opportunities to undergraduates. These experiences complement the classroom experience and prepare our students for careers in a wide range of industries.

The EET program at Michigan Tech has a state-of- the-art robotic automation laboratory, which allows faculty to provide students with training that meets industrial standards. Currently, the laboratory is equipped with four FANUC LR Mate Education Training Carts, and incorporates FANUC Robotics' latest-generation electric, servo-driven mini robot, housed in a self-contained, portable enclosure. The LR Mate Education Training Cart MH1 can be used to teach students how to program a real robot, in real time, in a safe, controlled environment. The FANUC robot is a highly upgradable system and allows demonstrating basic functions (e.g., vision, collision guard, path tracing, insert, straight line accuracy), as well as creating more advanced hands-on laboratories. While it is desirable to have more robots, the four units currently installed at Michigan Tech are sufficient to teach a class of 16 students with two lab sections. Current robot capacity is adequate to train and certify at least 8 industry representatives, students from other institutions, or displaced workers. This capability allows for program sustainability and expansion. Training revenue will be used to acquire new robots to further support program growth.

We propose to create a similar robotics laboratory at Bay College in this project. The new robotics laboratory consisting of three FANUC LR Mate carts will allow Bay College to: 1) introduce two robotics automation courses in the curriculum; 2) provide hands-on training to students; 3) train and certify students from other institutions, industry representatives, and displaced workers; 4) conduct seminars for K-12 teachers; and 5) conduct outreach activities for the high school students.

\section{Modes of Curriculum Adaptation}

The four certification programs in Industrial Automation: Handling Tool Operation and Programming, Roboguide, Robot Operations, and iRVision 2D, implemented at Michigan Tech and Bay College through this project, will attract prospective students, industry representatives and unemployed workers who want to re-tool their skills, and students from other universities and colleges without a certification program. The revenue received from these certification programs will serve as a main source of funds to sustain the project and to continually enhance and update the robotics automation programs at the partnering institutions. Due to the rapidly 
evolving technological world, robotics automation is currently developing at a fast pace. This pace will only increase in the near future. As a result, the demand for technologists in the field of robotics is also increasing. This growing demand for highly knowledgeable technologists from the industrial sector must be supported by educational units and, in particular, by technology programs which place an emphasis on hands-on training. To build highly effective and selfsustaining programs with broad impacts in robotics automation is not a simple task. Bay College and Michigan Tech have joined efforts to build this program and to make it highly adaptable by various institutions and with different budgets. The curriculum developed in this project and open-source training software "RobotRun" will enable three modes of adaptation, which are shown in Table 1. All three modes will allow any institution to teach robotics skills; modes one and two will also allow for industrial training and certification, which will enable the other new programs to grow and expand.

\begin{tabular}{|c|c|c|c|}
\hline Modes & $\begin{array}{l}\text { Institution } \\
\text { Budget }\end{array}$ & $\begin{array}{l}\text { Adapted Project Materials, } \\
\text { Hardware, and Software }\end{array}$ & Benefits \\
\hline Mode 1 & High & $\begin{array}{l}\text { 1. All Course Materials } \\
\text { 2. 3-4 Fanuc Industrial Robots } \\
\text { 3. FANUC Roboguide Software } \\
\text { 4. Project developed RobotRun } \\
\text { Software }\end{array}$ & $\begin{array}{l}\text { 1. Teach Robotics courses and certify students } \\
\text { 2. Provide hands-on training using industrial robots } \\
\text { 3. Train students on industrial and educational software packages } \\
\text { 4. Train and certify significant number of students from other } \\
\text { institutions, industry representatives and displaced workers. High } \\
\text { profit and possibility for fast expansion } \\
\text { 5. K-12 outreach activities }\end{array}$ \\
\hline Mode 2 & Medium & $\begin{array}{l}\text { 1. All Course Materials } \\
\text { 2. 1-2 Fanuc Industrial Robots } \\
\text { 3. FANUC Roboguide Software } \\
\text { 4. Project developed RobotRun } \\
\text { Software }\end{array}$ & $\begin{array}{l}\text { 1. Teach Robotics courses and certify students } \\
\text { 2. Provide hands-on training using industrial robots } \\
\text { 3. Train students on industrial and educational software packages } \\
\text { 4. Train and certify average number students from other institutions, } \\
\text { industry representatives and displaced workers. Medium profit and } \\
\text { possibility for slow expansion } \\
\text { 5. K-12 outreach activities }\end{array}$ \\
\hline Mode 3 & Low & $\begin{array}{l}\text { 1. All Course Materials } \\
\text { 2. Project developed RobotRun } \\
\text { Software }\end{array}$ & $\begin{array}{l}\text { 1. Teach Robotics courses } \\
\text { 2. Train students on educational software package } \\
\text { 3. K-12 outreach activities }\end{array}$ \\
\hline
\end{tabular}

Table 1: Modes of adaptation by other institutions

\section{Year 1 Project Progress}

Michigan Tech and Bay College have actively collaborated during the initial phase (Year 1) of this project and achieved significant advancements in the proposed activities. Tables 2 and 3 provide details on which activities have already been accomplished or planned to be completed by the end of the fiscal year at the Michigan Tech and partner Bay Community College.

\begin{tabular}{|l|l|}
\hline Activity & Status/Due \\
\hline Get FANUC educational kits and install them on the robots & DONE \\
\hline Meeting with partner institution Fall 2015 & DONE \\
\hline Participate in ATE PI Conference & DONE \\
\hline Meeting with Bay College Spring 2016 & May 15 \\
\hline Submit the abstracts to ASEE 2016 annual conference & DONE \\
\hline $\begin{array}{l}\text { Develop an Articulation Agreement between Michigan Tech and Bay } \\
\text { College }\end{array}$ & June 1 \\
\hline
\end{tabular}




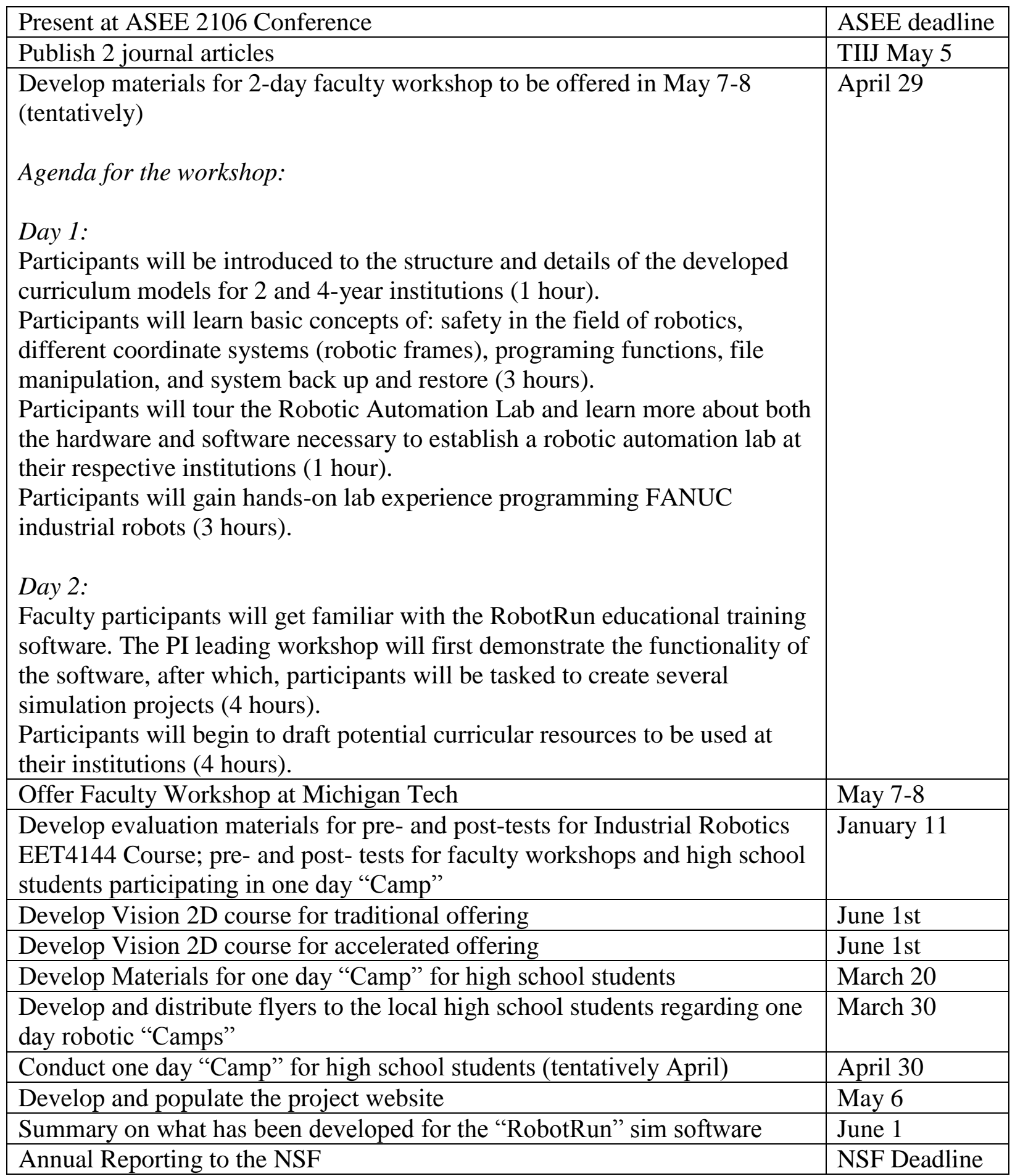

Table 2 Year 1 Project Activities at Michigan Tech

\begin{tabular}{|l|l|}
\hline Activity & Status/Due \\
\hline Purchase and install Fanuc robots and educational kits & DONE \\
\hline Meeting with Michigan Tech Fall 2015 & DONE \\
\hline
\end{tabular}




\begin{tabular}{|l|l|}
\hline Participate in ATE PI Conference & DONE \\
\hline Faculty Training at FANUC & DONE \\
\hline Meeting with Michigan Tech Spring 2016 & May 15 \\
\hline Submit the abstract to ASEE 2016 annual conference & DONE \\
\hline Adapt \& Modify already developed Real Time Robotics course & May 6 \\
\hline $\begin{array}{l}\text { Create 3 new labs for Real Time Robotics Course and share them with } \\
\text { Michigan Tech }\end{array}$ & April 30 \\
\hline $\begin{array}{l}\text { Adapt the currently developed materials at Michigan Tech and develop } \\
\text { additional 4 lectures and 3 labs for Robotics Vision Course }\end{array}$ & May 6 \\
\hline $\begin{array}{l}\text { Develop Articulation Agreement between Michigan Tech (EET program) } \\
\text { and Bay College }\end{array}$ & May 6 \\
\hline Prepare and submit the paper for ASEE 2016 ASEE conference & ASEE deadline \\
\hline $\begin{array}{l}\text { Participate in 2 day faculty training workshop conducted at Michigan Tech } \\
\text { in Spring 2016 }\end{array}$ & May 7-8 \\
\hline Annual Reporting to the NSF & NSF Deadline \\
\hline
\end{tabular}

Table 3 Year 1 Project Activities at Bay College

\section{Conclusion}

The primary merit described in this paper NSF sponsored initiative between Michigan Tech and Bay Community College is in how it reaches EET (two- and four-year) students with current concepts and hands-on practices in Industrial Robotics that meet current industry needs. There is significant demand from industry for well-prepared specialists capable of programming, maintaining, and troubleshooting modern robots. As a result, the goal is to develop a model curriculum and associated tools that can address current and future industry expectations. In addition to enhancing STEM education at the college level, this collaborative project will provide a template for how other institutions can bridge the gap between academia and industry, and academia and K-12. These bridges are critical for providing new resources to recruit and prepare a sustainable pipeline of graduates in robotics automation. Short-term outcomes include: models for outreach that encourage early STEM interest, two certificates endorsed by industry, and faculty development workshops to reach other universities and colleges.

Development of an advanced, industry-driven, hands-on educational curriculum in robotic automation will improve the quality of STEM education for EET students at two- and four-year institutions. The "RobotRun" software developed will be freely available for adaptation, which will allow robotics to be taught even when the purchase of industrial robots is not feasible. Faculty development will include extensive training and industrial certification in robotics and automation. Partnership with FANUC will create an important ongoing link between academia and industry to ensure the curriculum is regularly updated to meet emerging needs. K-12 teacher seminars will introduce advances in technology to those who play a pivotal role in inspiring future generations of engineering technologists. The new robotics courses and equipment obtained via this collaboration will attract interest of K-12 teachers and students, while simultaneously advancing undergraduate learning. Collaboration and dissemination will align Michigan Tech robotic automation education with industry needs. As a result of the project, 
engineering technologists will enter the workforce prepared to adapt to the complex and changing demands of tomorrow's high-tech workplace.

\section{Acknowledgement}

This work is supported by the National Science Foundation, ATE; Grant number DUE-1501335.

\section{References:}

1. International Federation of Robotics: Metra Martech Study on Robotics (http://www.ifr.org/uploads/media/Metra_Martech_Study_on_robots_02.pdf)

2. International Federation of Robotics (http://www.ifr.org)

3. Apple Inc., (http://appleinsider.com/articles/13/11/13/apple-investing-record-105-billion-on-supply-chain-robotsmachinery)

4. ManpowerGroup : Annual Talent Shortage Survey (http://www.manpowergroup.com/talent-shortageexplorer/\#.VAnGjvmwJ8E)

5. American Society for Training and Development Report (http://www.astd.org/Professional-Resources/State-OfThe-Industry-Report)

6. F.P. Deek, F.P., Kimmel, H., \& McHugh, J., "Pedagogical changes in the delivery of the first course in computer science: Problem solving, then programming”, Journal of Engineering Education, 87, 3, pp. 313-320, July 1998.

7. Replacement needs in 2008-18, 2008 National Employment Matrix title and code, Bureau of Labor Statistics http://www.bls.gov/emp/ep_table_110.htm

8. D.Liming and M.Wolf, "Job Outlook by Education 2006-16", Office of Occupational Statistics and Employment Projections, BLS

9. N. Terrell, the Office of Occupational Statistics and Employment Projections, "STEM Occupations", Occupational Outlook Quarterly 2007, BLS

10. Occupational Outlook Handbook www.bls.gov/oco.

11. J. Kuenzi, C.Matthew, and B. Mangan, "Science, Technology, Engineering, and Mathematics (STEM) Education Issues and Legislative Options", CRS Report for Congress, 2006.

12. Bonvillian, W. B. "Science at a crossroads", The Federation of American Societies for Experimental Biology Journal, 16, 915-921, 2002.

13. Gonzales, P., Guzmán, J. C., Partelow, L., Pahlke, E., Jocelyn, L., Kastberg, D., \& Williams, T., "Highlights from the Trends in International Mathematics and Science Study (TIMSS)", Washington, DC: U.S. Department of Education, National Center for Education Statistics, 2003.

14. Lemke, M., Sen, A., Pahlke, E., Partelow, L., Miller, D., Williams, T., Kastberg, D., \& Jocelyn, L. "International outcomes of learning in mathematics literacy and problem solving: PISA 2003 results from the U.S. perspective", Washington, DC: U.S. Department of Education, National Center for Education Statistics, 2004.

15. Office of Science and Technology Policy, Domestic Policy Council, American Competitiveness Initiative - Leading the World In Innovation, 2006.

16. M. Matari'c, N.Koenig, and D.Feil-Seifer, "Materials for Enabling Hands-On Robotics and STEM Education", American Association for Artificial Intelligence, 2007.

17. Whitman, L.E.; Witherspoon, T.L.; , "Using legos to interest high school students and improve k12 stem education," Frontiers in Education, 2003. FIE 2003. 33rd Annual , vol.2, no., pp. F3A_6F3A_10, 5-8, 2003.

18. B. Barker and J.Ansorge, "Robotics as Means to Increase Achievement Scores in an Informal Learning Environment, Journal of Research on Technology in Education 39(3), 229-243, 2007.

19. Nourbakhsh, I., Crowley, K., Bhave, A., hamner, E., Hsium, T., Perez-Bergquist, A., Richards, S., \& Wilkinson, K., "The robotic autonomy mobile robots course: Robot design, curriculum design, and educational assessment", Autonomous Robots, 18(1), 103-127, 2005.

20. Beer, R. D., Chiel, h. J., \& Drushel, R., "Using robotics to teach science and engineering", Communications of the ACM, 42(6), 85-92, 1999.

21. Barnes, D. J., "Teaching introductory Java through Lego Mindstorms models", Proceedings of the 33rd SIGCSE Technical Symposium on Computer Science Education,2002. 
22. Robinson, M, "Robotics-driven activities: Can they improve middle school science learning?", Bulletin of Science, Technology \& Society, 25(1), 73-84, 2005.

23. Rogers, C., \& Portsmore, M.,"Bringing engineering to elementary school", Journal of STEM Education, 5(3\&4), 17-28, 2004.

24. Mauch, E.,"Using technological innovation to improve the problem solving skills of middle school students", The Clearing House, 75(4), 211-213, 2001.

25. Papert, S., "Mindstorms: Children, computers, and powerful ideas", New York: BasicBooks, Inc., 1980

26. http://www.worldrobotics.org/downloads/2009_First_News_of_Worldrobotics.pdf

27. Johnson, J., "Children, robotics, and education”, Artificial Life and Robotics, 7 (1-2), pp. 16-21.

28. Fernandez, K., “NASA summer robotics interns perform simulation of robotics technology”, Proceedings of ASEE AC 2009-328.

29. Ciaraldi, M., "Robotics engineering: a new discipline for a new century", Proceedings of ASEE AC 2009-997.

30. Alimisis, D., "Technical school students design and develop robotic gear-based constructions for the $\mathrm{t}$ ransmission of motion”, In Gregorczyk G., WalatA., Borowiecki M., (eds.), Eurologo 2005, Digital Tools for Lifelong Learning, Proceedingd, Warsaw: DrukSfera, pp. 76-86

31. Chang, D., "Educating generation Y in robotics", Proceedings of ASEE AC 2009-750.

32. Liu, Y., "From handy board to VEX: the evolution of a junior-level robotics laboratory course", Proceedings of ASEE AC 2009-1890.

33. Karatrantou, A, "Introduction in basic principles and programming structures using the robotic constructions LEGO Mindstorms", Tzimogiannis A., Proceedings of the $3^{\text {rd }}$ National Conference, Teaching Informatics, University of Peloponnese.

34. Eslami, A., "A remote-access robotics and PLC laboratory for distance learning program", Proceedings of ASEE AC 2009-1410.

35. Ren, P., "Bridjing theory and practice in a senior-level robotics course for mechanical and electrical engineers", Proceedings of ASEE AC 2009-671.

36. Piaget, J. “To Understand Is To Invent”, N.Y.: Basic Books, 1974

37. You, Y., "A project-oriented approach in teaching robotics application engineering", Proceedings of ASEE AC 2009-2354.

38. Michalson, W., "Balancing breadth and depth in engineering education: unified robotics III and IV", Proceedings of ASEE AC 2009-1681.

39. Ciaraldi, M., "Designing an undergraduate robotics engineering curriculum: unified robotics I and II", Proceedings of ASEE AC 2009-1161.

40. Devine, K., "Integrating robot simulation and off-line programming into an industrial robotics course", Proceedings of ASEE AC 2009-2159.

41. Schneider, R., "Robotic Automation Can Cut Costs", Manufacturing Engineering. Vol. 135 No. $6 ., 2005$

42. Jones, T., "Trends and Motivations for Robot Purchases", www.robotics.org, 2006

43. Morey, B. "Robotics Seeks Its Role in Aerospace”, Manufacturing Engineering. Vol. 139 No. 4., 2007.

44. Nieves, E., "Robots: More Capable, Still Flexible”, Manufacturing Engineering. Vol. 134 No. $5,2005$.

45. Tolinski, R., "Robots Step Up to Machining”, Manufacturing Engineering. Vol. 137 No. 3., 2006.

46. Devine, K., “Agile Robotic Work Cells for Teaching Manufacturing Engineering”, Proceedings of ASEE, 2009.

47. Stienecker, A., "Applied industrial robotics: a paradigm shift”, Proceedings of ASEE, 2008.

48. https://www.lssu.edu/programsofstudy/engineering-manufact/

49. http://www.mlive.com/michigan-jobsearch/index.ssf/2010/02/its official_michigan is the toughest_pl.html

50. Watson, J. B. and Rossett, A. (1999). "Guiding the Independent Learner in Web-Based Training, Educational Technology," Vol. 39, Number 3, May 1999.

51. Completing College:Assesing Graduation Rates at Four-Year Institutions (http://heri.ucla.edu/prdisplay.php?prQry=80)

52. FANUC Autorized Sattellite Training Program (F.A.S.T) http://robot.fanucamerica.com/supportservices/robotics-training/schools.aspx 